\title{
Technique Advances in
} Enteroatmospheric Fistula Isolation After Open Abdomen: A Review and Outlook

\author{
Jinjian Huang ${ }^{\dagger}$, Huajian Ren ${ }^{\dagger}$, Yungang Jiang, Xiuwen $W u^{*}$ and Jianan Ren* \\ Research Institute of General Surgery, Jinling Hospital, School of Medicine, Southeast University, Nanjing, China
}

\section{OPEN ACCESS}

Edited by:

Arnulf Gregor Willms,

Zentralkrankenhaus der

Bundeswehr, Germany

Reviewed by:

Yunfeng Cui.

Tianjin Hospital of ITCWM Nankai

Hospital, China

Uwe Klinge,

University Hospital RWTH

Aachen, Germany

Christoph Guesgen,

Bundeswehrkrankenhaus in

Koblenz, Germany

*Correspondence:

Xiuwen Wu

lygwxw@163.com

Jianan Ren

jiananr@gmail.com

tThese authors have contributed equally to this work

Specialty section: This article was submitted to Visceral Surgery,

a section of the journal

Frontiers in Surgery

Received: 06 May 2020 Accepted: 03 December 2020

Published: 20 January 2021

Citation:

Huang J, Ren H, Jiang Y, Wu X and Ren J (2021) Technique Advances in

Enteroatmospheric Fistula Isolation

After Open Abdomen: A Review and

Outlook. Front. Surg. 7:559443.

doi: 10.3389/fsurg.2020.559443
Enteroatmospheric fistula (EAF) after open abdomen adds difficulties to the management and increases the morbidity and mortality of patients. As an effective measurement, reconstructing gastrointestinal tract integrity not only reduces digestive juice wasting and wound contamination, but also allows expedient restoration of enteral nutrition and intestinal homeostasis. In this review, we introduce several technologies for the temporary isolation of EAF, including negative pressure wound therapy, fistuloclysis, fistula patch, surgical covered stent, three-dimensional (3D) printing stent, and injection molding stent. The manufacture and implantation procedures of each technique with their pros and cons are described in detail. Moreover, the approach in combination with finger measurement, x-ray imaging, and computerized tomography is used to measure anatomic parameters of fistula and design appropriate 3D printer-recognizable stereolithography files for production of isolation devices. Given the active roles that engineers playing in the technology development, we call on the cooperation between clinicians and engineers and the organization of clinical trials on these techniques.

Keywords: open abdomen, enteroatmospheric fistula, fistula isolation, biomedical device, 3D printing

\section{INTRODUCTION OF OPEN ABDOMEN THERAPY}

The open abdomen therapy can be chosen for severe intraabdominal infections and abdominal compartment syndrome (ACS) when no other perceived options exist. This strategy allows surgeons to carry out source control procedures on unexplored abdominal infections and reduce intraabdominal pressure for the prevention of visceral organ ischemia (1). Early closure of abdomen is highly recommended once patients' conditions are improved because open abdomen therapy can alter the normal physiological states of abdomen and cause wound infections, seromas, fistula formation, recurrence of the defect, and even death (2-4). Primary fascia closure is an ideal solution to realize the abdominal closure, but in the presence of large fascia defects, temporary abdominal closure (TAC) can be alternatively applied including Bogotà bag, skin closure, Wittmann patch, Barker vacuum pack, commercial negative pressure wound therapy (NPWT), and commercial NPWT plus mesh-mediated traction (5). A clinical investigation from the International Register of Open Abdomen (IROA) study group indicated that NPWT was the most frequent choice $(46.8 \%)$ for TAC $(6,7)$ because it facilitated the formation of wound granulation, prevention of fistula formation, and reduction of wound contaminations $(8,9)$. 
Even with these interventions, the occurrence of enteroatmospheric fistula (EAF) still reached $9 \%$ and the overall mortality rate in the entire population was $29.7 \%$. In the subgroup analysis, it was revealed that EAF raised the death rate from 28.8 to $39 \%$, suggesting that EAF was an independent risk factor of mortality as it can lead to the loss of digestive fluid and other complications including wound contamination, water-electrolyte disturbance, troubles in enteral nutrition, and hyper-metabolic conditions as well as chronic intestinal failure $(10,11)$. Moreover, once the mucosa is protruded, EAF cannot be closed spontaneously and has to be resected until the patient has recovered and the wound completely heals (12). For this reason, fistula isolation is very important to ensure the safety of patents waiting for definite fistula surgeries.

\section{EMERGING TECHNIQUES FOR EAF ISOLATION}

EAF requires comprehensive treatments: (1) nutritional support, among which the early total parenteral nutrition is beneficial for intestinal rest and spontaneous fistula closure; (2) somatostatin analogs, which reduce gastrointestinal (GI) secretions and allow fast fistula closure, but do not reduce the mortality. Most of the studies agree that the greatest benefit occurs in the first 10 days of treatment $(13,14)$; (3) antibiotics, whose application should follow the Surviving Sepsis guidelines, and empiric coverage should not exceed 4 to 7 days $(15,16)$; (4) maintenance of water and electrolyte balance. Fluid infusion is administered based on a general analysis of fistula's output and body fluid balance; (5) others, such as fibrin glue, endoscopic clips, and fistula plug can be considered the adjuvant therapy for non-operative fistula closure (17-20). In addition, various EAF isolation approaches have been invented for improving the wound protection and maintaining the GI homeostasis, therefore playing increasing therapeutic roles.

\section{NPWT}

NPWT has been widely used for TAC in clinical practice. Firstly, the skin necrosis and any other necrotic tissues need to be debrided. Secondly, an obligatory non-adherent polyvinyl alcohol membrane serves as the first layer of NPWT over the intestinal loops and a piece of white sponge as the second. The non-adherent layer can effectively prevent the adhesion between the intestinal loops and the sponge. It is worth noting that the sponge needs to be tailored slightly smaller than the size of abdominal wound to leave enough space for abdominal wall traction. If there are any skin folds, stoma and drainage tubes, the stoma pastes or silicone gels are required to make the entire negative pressure system sealed. Finally, the adhesive drape is placed over the sponge with the margins of intact skin. An external negative pressure is

Abbreviations: EAF, enteroatmospheric fistula; NPWT, negative pressure wound therapy; CT, computerized tomography; STL file, stereolithography file; ACS, abdominal compartment syndrome; TAC, temporary abdominal closure; GI, gastrointestinal; FDM, fused deposition model; PLA, polylactic acid; TPU, thermoplastic polyurethane; MRI, magnetic resonance imaging. chosen ranging from -100 to $-125 \mathrm{mmHg}$ to drain the intestinal fluids according to their output, the number of EAFs, the amount of NPWT, and the process of wound healing (21). The whole equipment for NPWT is described in Figure 1A, which has been commercially available from KCI (TX, USA). Figure 1B shows the practice of NPWT in our medical center.

Although treated with NPWT, the spontaneous closure of EAF is very rare and depends on the fistula location and output $(22,23)$. Once the mucosal protrusion of EAF occurs, spontaneous closure becomes impossible, and the only chance for patients is to survive with the intention of further surgery. In this situation, further aggressive approaches can be considered if a satisfied source control has not been achieved. For example, Foley catheter can be placed directly into the intestine lumen and pulled out through holes in every layer of the NPWT dressing (Figure 1C), which enables drainage of high-output fistula and achieves a more satisfying result than the NPWT alone (21). Similarly, the silicone fistula adapter (SFA) has been invented by PPM Fistelapater to realize the isolation of fistula opening in combination with NPWT (Figures 1D,E) and drains the EAF more efficiently (24).

\section{Fistuloclysis}

Management of EAF requires sufficient nutritional and metabolic supports by the means of gradual transition from parenteral nutrition to enteral nutrition. Long-term parenteral nutrition may lead to complications such as the catheter-related bloodstream infections, liver injury, and intestinal dysfunction, while enteral nutrition can improve those conditions. As an enteral nutrition routine, fistuloclysis can be used to infuse enteral nutrients, formula, or proximal GI secretions to the distal limb of fistula in order to improve the nutritional status and maintain fluid/electrolyte homeostasis $(25,26)$. Figure 2 shows that this technique was applicable in granulating the open abdomen with EAF in our medical center. It was revealed by Mettu et al. (27) that fistuloclysis could replace the parenteral nutrition and reduce the cost of nutritional support. For these critically ill surgical patients, fistulaclysis allows early enteral nutrition, which improves prognosis through improvements of intestinal barrier functions and immune states $(28,29)$.

However, fistuloclysis has been less popular in recent years mainly due to technical and aesthetic concerns (30). Some EAFs are not appropriate for fistuloclysis because of their distal locations or failure in the placement of feeding tubes. In addition, this approach is accomplished with risks of the tube dislocation, effluent deterioration, and wound contamination, thus consuming large amounts of nursing work. Through combining with NPWT, it facilitates the control of fistula effluent and fixation of fistuloclysis tube, which makes fistuloclysis safer (31). Collectively, our opinion is to carry out this technique if enteral nutrition is achieved especially when EAF is located in the proximal part of small intestine, and this approach will enhance the physical strength of patients to tolerate definite surgery. 
A

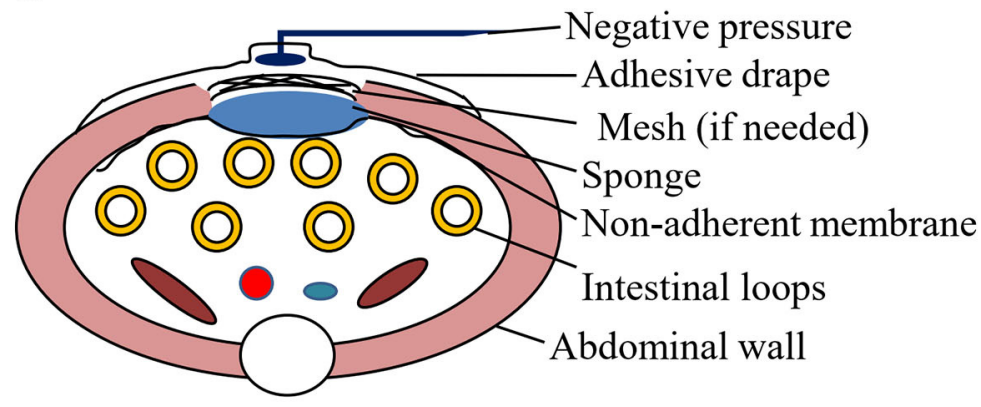

B

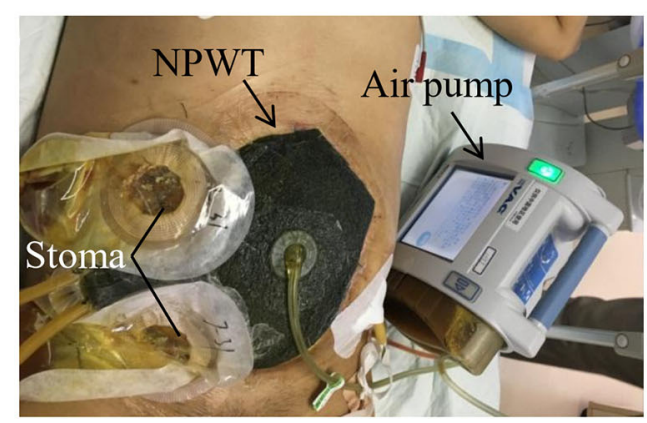

C

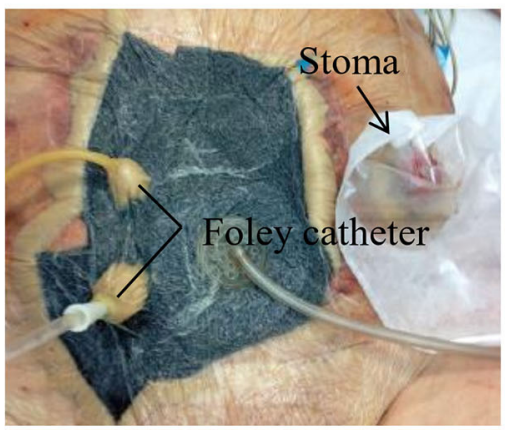

D

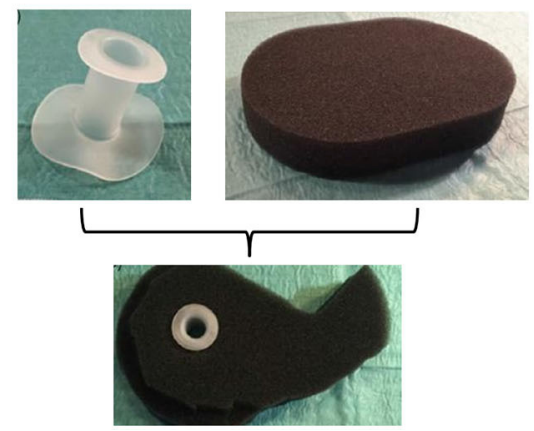

E

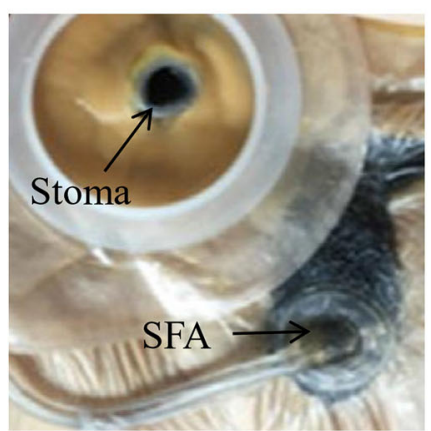

FIGURE 1 | NPWT for EAF isolation. (A) The schematic diagram of the vacuum-assisted closure (VAC) device for NPWT. (B) The patient with EAF received NPWT in our medical center. The use of picture was approved by the patient. (C) Foley catheter can enhanced the drainage of EAF with protruded mucosa. Reproduced with the permission from Bobkiewicz et al. (D,E) The real product of the silicone fistula adapter (SFA) and its application in EAF for an efficient drainage. Reproduced with the permission from Wirth et al.

\section{Fistula Patch}

Compared with fistuloclysis, intraluminal occlusion of EAF is more advantageous since it supports the physical integrity of GI tract and ensures the pass of digestive contents with less leakage from EAF. Fistula patch is the first-generation device that addresses this issue. As shown in Figure 3A, the patch is made of two pieces of silica gels embedded with a polypropylene mesh, combining the materials' elasticity and plasticity. This design enables the rolling of the patch for implantation as well as rapid shape recovery in the intestinal lumen (Figure 3B).

Notably, the patch can only be applied to the EAFs with mucosal protrusion and needs to be tailored in accordance with their anatomic characteristics. Figure 3C shows a patient treated with the fistula patch, which was fixed above the abdominal wounds using a tube. A study from our medical center revealed that this technique could help restore enteral nutrition and reduce the effluent of EAF (32). However, only around half of patients were suitable for this treatment because of the implanting difficulties and anatomic complexity of EAFs. Moreover, the safety concerns regarding this technique have also been raised particularly in these patients with intestinal edema or anatomic mismatch of the patch to the EAF. This is because under those conditions, the intestinal wall is prone to the physical cutting of the patch edge (Figure 3D), leading to GI rupture and bleeding, although these complications are rare.

\section{Fistula Stent}

More insights have been put on the fistula stent that can be made tubularly and conforms to the shape of intestinal tract. As shown in Figure 4, Rebibo et al. (33) reported a covered self-expanding metal stent (Hanarostent HRC, Life Partners Europe, Bagnolet, France) to close the EAF. This stent was implanted through a terminal ileostomy assisted by a guide wire and the endoscopy. Three patients received this treatment and regained the enteral nutrition. Combined with NPWT, two of them achieved the spontaneous closure of EAF, and then the stent could be removed in the assistance of endoscopy. This study preliminarily indicated the effectiveness of the covered self-expanding metal stent. However, pre-existing ileostomy and complicated implanting process greatly limit the indication of this management for EAF.

Our medical center explored a novel approach that extended the application of fistula stent to patients without ileostomy by using a $3 \mathrm{D}$ printing technique (34-37). This technique was based on a fused deposition model (FDM) in which the thermoplastic polyurethane (TPU) filament was melted and reshaped as desired. To obtain an appropriate stent, the first step was to investigate the anatomic parameters of EAF. Three methods can be used to measure the EAF including the finger palpation, x-ray imaging, and computerized tomography (CT) (Figure 5A). The finger palpation is the most direct way. By 


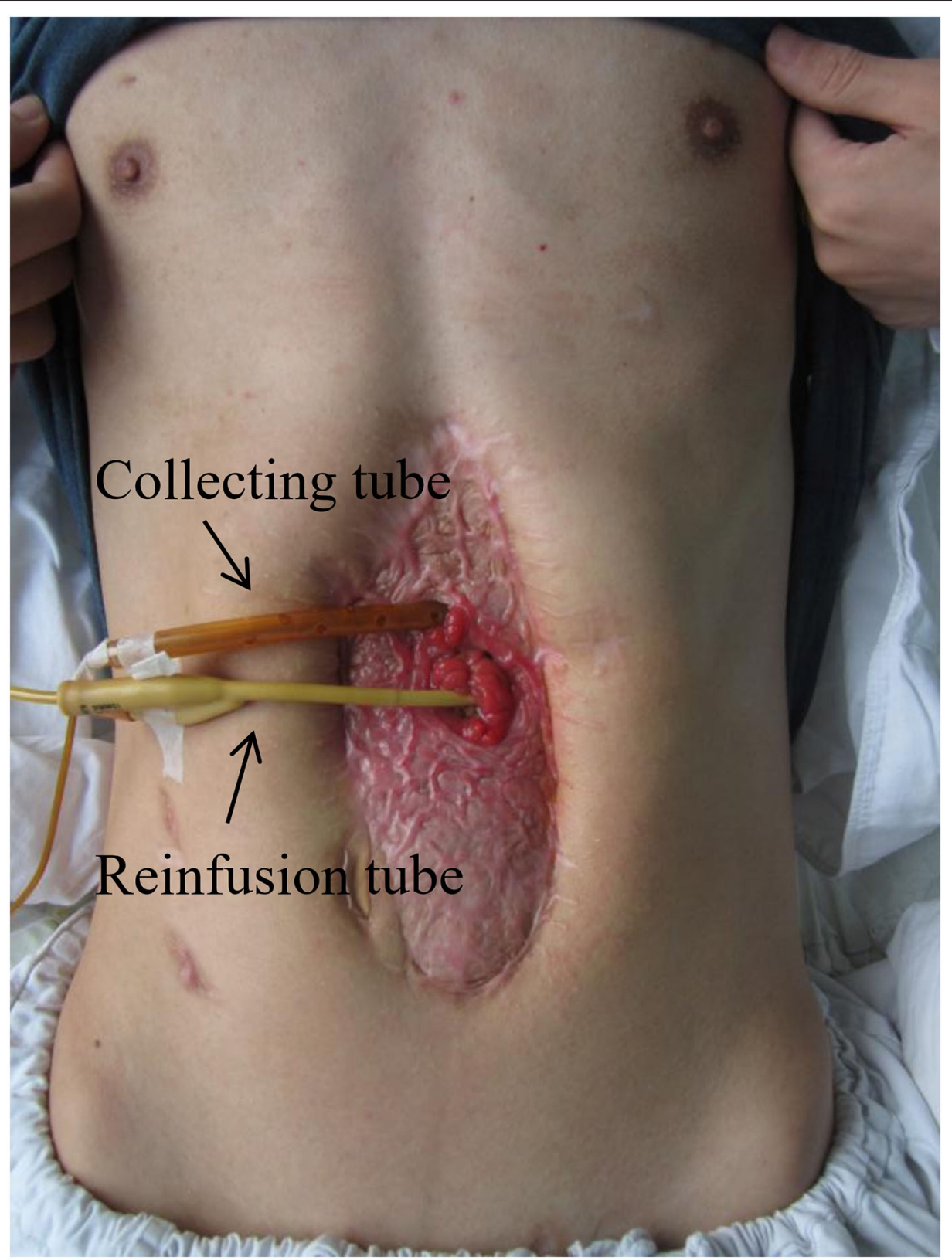

FIGURE 2 | Fistuloclysis for the restoration of enteral nutrition. This patient was treated with open abdomen (grade 4, frozen abdomen) and the effluent was immediately reinfused into distal limb of EAF. The use of picture was approved by the patient.

wearing sterile gloves, fingers can reach into the intestinal lumen though the EAF orifice; however, this does not always work when the orifice is too small or the intestinal lumen is too narrow. Moreover, due to the inaccurate and limited touch, some tiny fistulas are easily omitted. Fistulography by the $\mathrm{x}$-ray imaging can be used to detect these tiny fistulas and achieve a general view toward the GI tract integrity (38). Contrast-mediated high resolution CT is a more advantageous method not only due to its high sensitivity for the fistula (39), but also because the images can be reconstructed in $3 \mathrm{D}$ so that we are able to visualize the anatomic parameters of EAF (34). The goal of these detection approaches is to obtain the diameters of proximal and distal limbs $\left(\mathrm{L}_{1}, \mathrm{~L}_{2}\right)$ and their resulting angle $(\beta)$ in order to design a suitable stereolithography (STL) file based on the measurements (Figure 5B). This STL file can be recognized by an FDM 3D printer to print a fistula stent made of TPU (Figure 5C). Because of the elasticity of TPU, the resulting stent can be remodeled during the implantation (Figure 5D). Figure 5E demonstrates a case who received a $3 \mathrm{D}$ printing fistula stent for isolation of the EAF. This treatment allowed the patient to restore the 

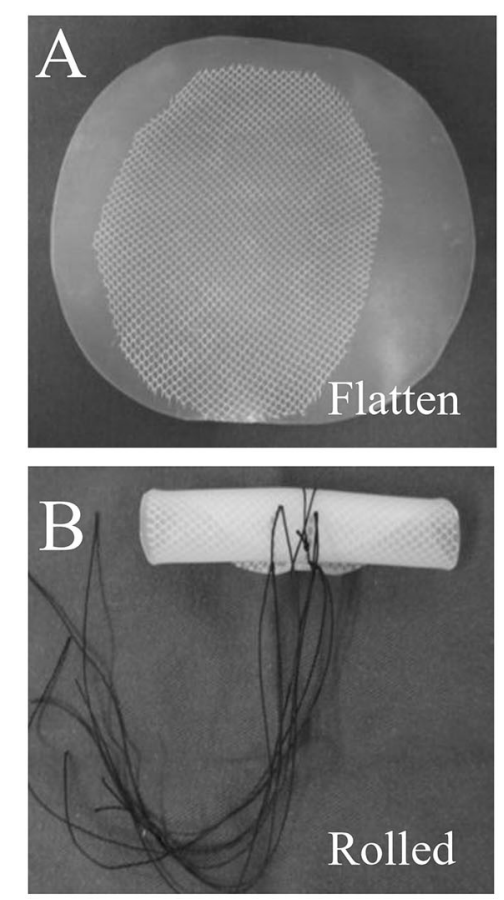
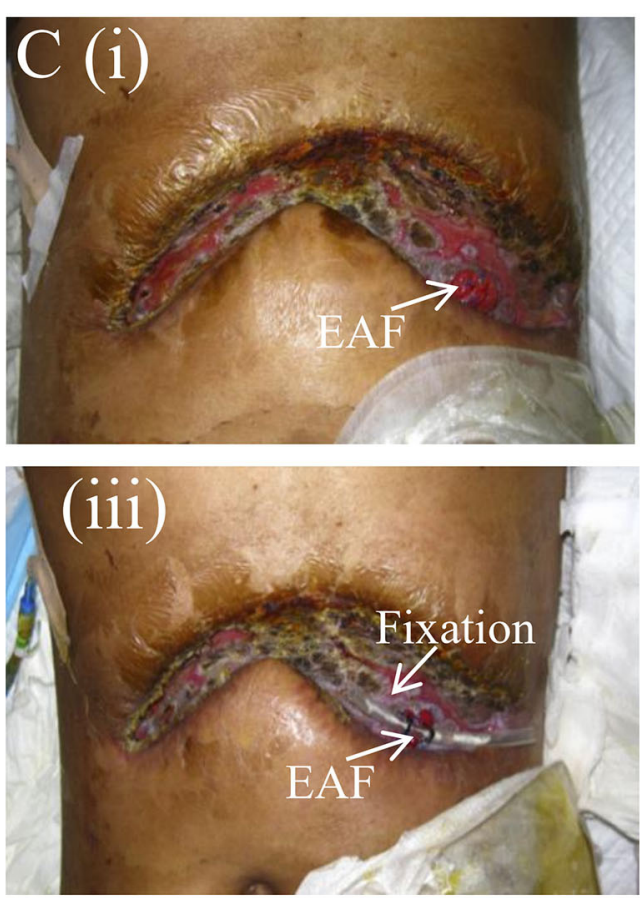
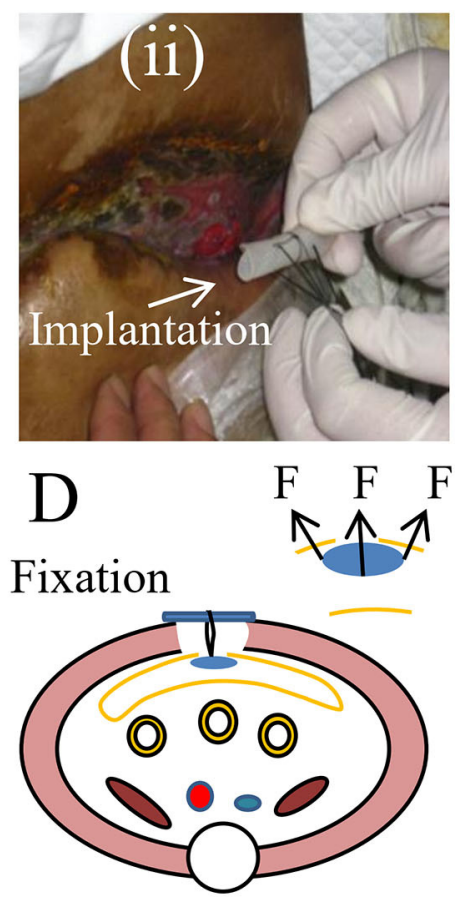

FIGURE 3 | Fistula patch for the occulsion of EAF. (A) The appearance of fistula patch. (B) The fistula patch needs to be rolled up for implantation. (C) The patients with EAF received the treatment of fistula patch that was fixed using a tube. Reproduced with the permission from Wang et al. (D) The schematic diagram of the fistula patch application and fixation. It highlights the potential risks for cutting the intestinal wall caused by the patch edge.
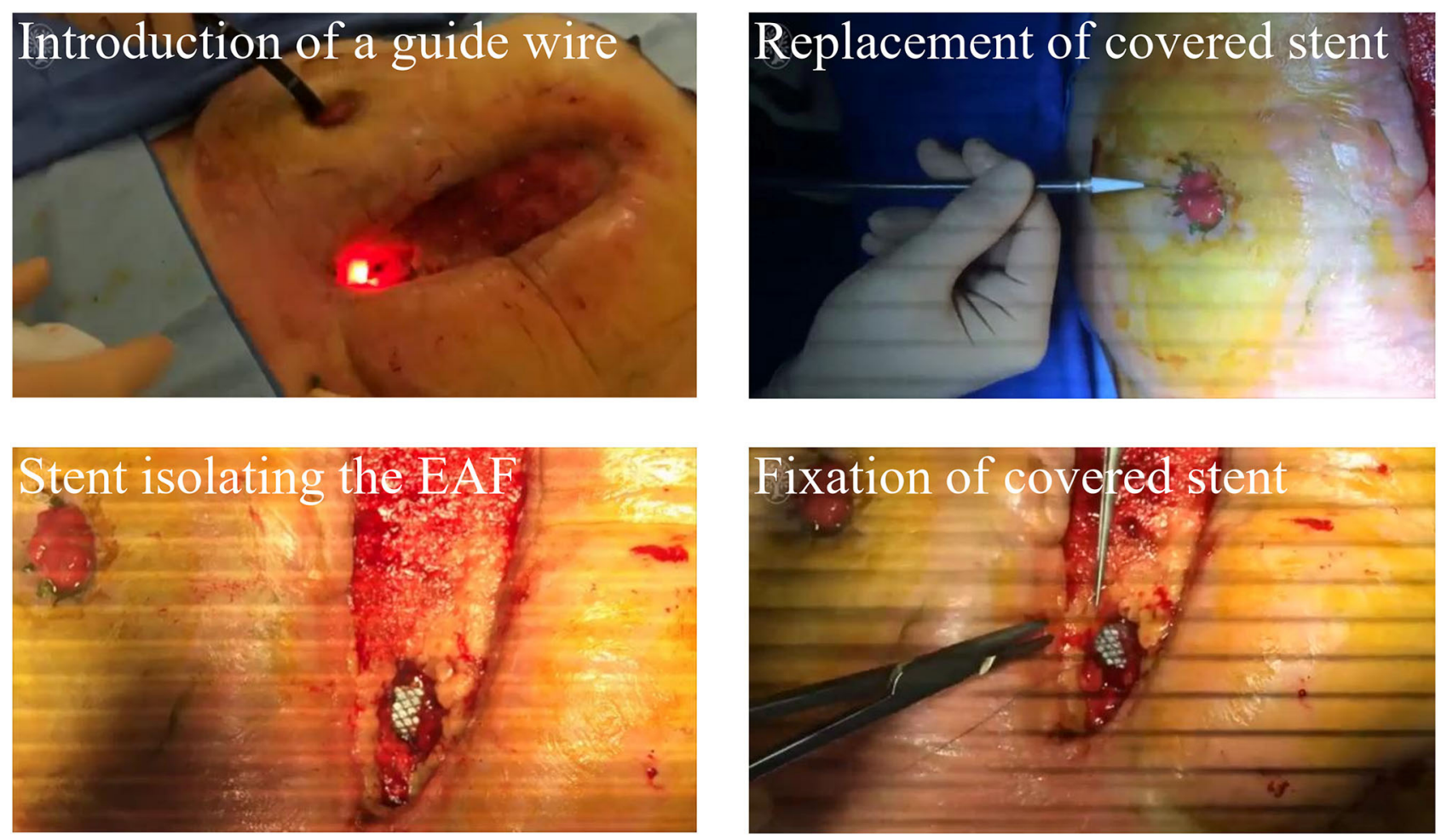

FIGURE 4 | A commercial covered self-expanding metal stent was used to isolate the EAF. Reproduced with the permission from Rebibo et al. 


\section{A \\ Parameter investigation}

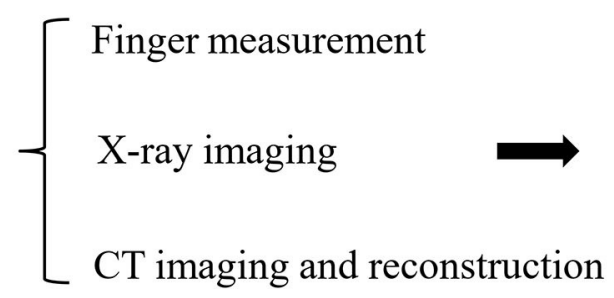

B

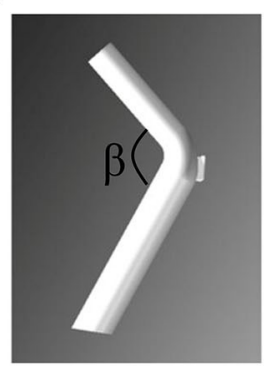

C

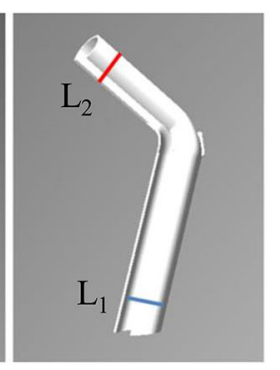

$c$

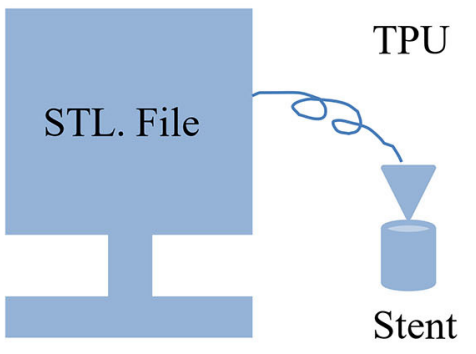

D
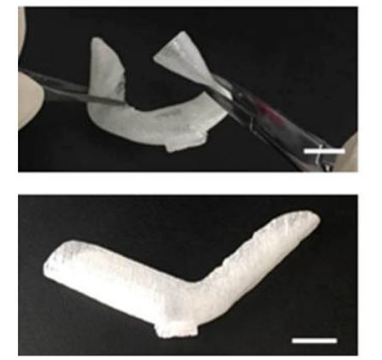

E

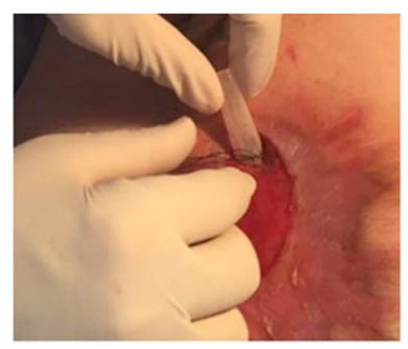

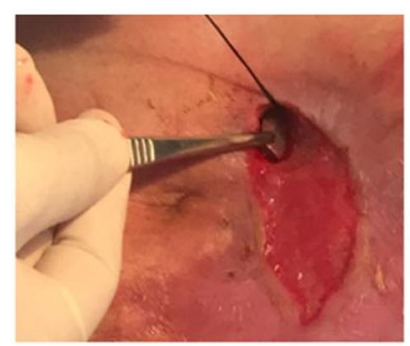

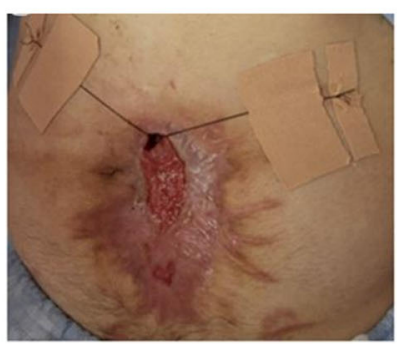

FIGURE 5 | 3D printing stent for the isolation of EAF. (A) The methods to measure the anatomic parameters of EAF. (B) The STL file of stent designed using Solidwork software according to the measurement of EAF anatomy. (C) The schematic diagram of a 3D printer run in the FDM model to print the stent. (D) Implantability of the stent due to its shape flexibility. (E) The process of the stent implantation and fixation. Reproduced with the permission from Huang et al.
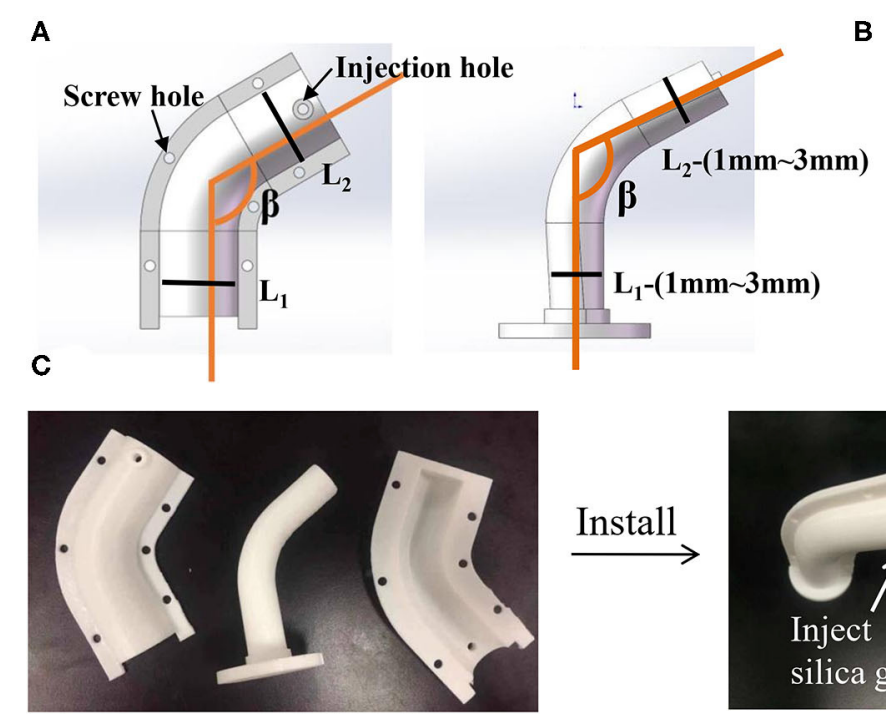

B
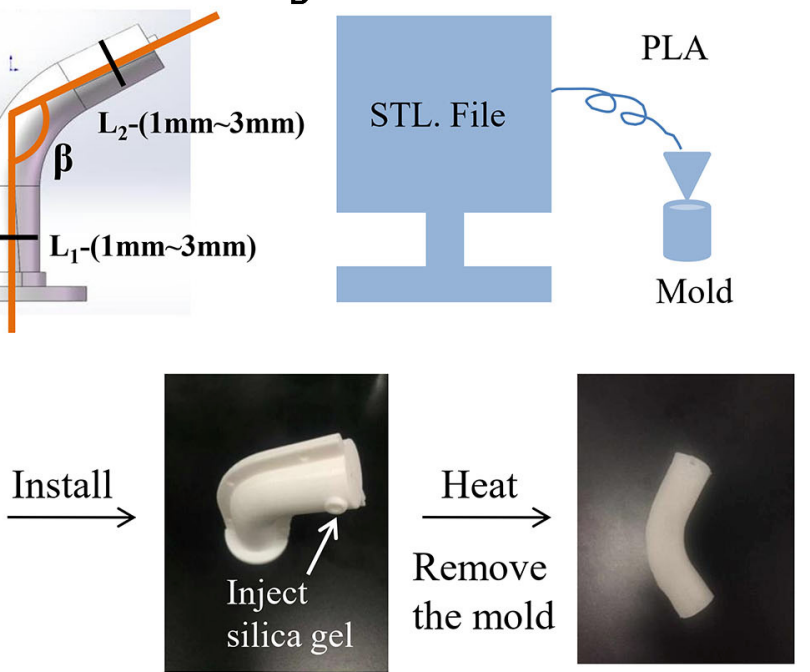

D
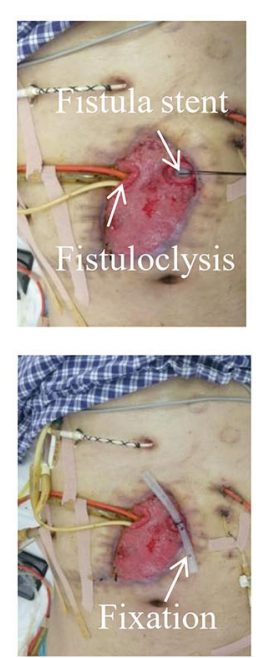

FIGURE 6 | Injection molding stent as a universal approach for the isolation of EAF. (A) The STL file of mold designed by Solidwork software according the measurement of EAF anatomy. (B) The schematic diagram of an FDM 3D printer printing the mold. (C) The real product of the printed mold and the stent that was casted from the mold. (D) The application of an injection molding stent in combination with fistuloclysis for the treatment of multiple EAFs. The use of picture was approved by the patient.

enteral nutrition, reduce the effluent, and feel free when doing some exercise for the recovery of physical strength. Notably, the anatomic features of EAF may be altered with the change of intestinal adhesion; therefore, a new stent is needed at this situation to replace the old, particularly in case the effluent greatly increased. Considering the implanting difficulties, the stent is 
TABLE 1 | Comparisons of fistula isolation approaches.

\begin{tabular}{|c|c|c|c|c|c|c|}
\hline & NPWT & Fistuloclysis & Fistula patch & $\begin{array}{l}\text { Covered metal } \\
\text { stent }\end{array}$ & 3D printing stent & $\begin{array}{l}\text { Injection } \\
\text { molding stent }\end{array}$ \\
\hline $\begin{array}{l}\text { Commercially } \\
\text { available }\end{array}$ & Yes & Yes & Yes & Yes & No & No \\
\hline $\begin{array}{l}\text { Average time for } \\
\text { device preparation } \\
\text { and implantation } \\
\text { (hour) }\end{array}$ & 0.5 & 0.2 & 0.2 & Not known & $12-24$ & 1 \\
\hline Contraindications & Not specific & $\begin{array}{l}\text { Fistula distally } \\
\text { located; distal tract } \\
\text { not accessed. }\end{array}$ & Small fistula orifice & $\begin{array}{l}\text { Without intestinal } \\
\text { stoma }\end{array}$ & Small fistula orifice & Small fistula orifice \\
\hline $\begin{array}{l}\text { Potential technical } \\
\text { risks }\end{array}$ & Not specific & $\begin{array}{l}\text { Chyme } \\
\text { contamination }\end{array}$ & $\begin{array}{l}\text { Mechanical } \\
\text { damage to } \\
\text { adherent mucosa }\end{array}$ & $\begin{array}{l}\text { latrogenic injury } \\
\text { (endoscopic } \\
\text { perforation) }\end{array}$ & $\begin{array}{l}\text { latrogenic injury } \\
\text { during } \\
\text { implantation }\end{array}$ & $\begin{array}{l}\text { latrogenic injury } \\
\text { during } \\
\text { implantation }\end{array}$ \\
\hline Clinical evidence & High & Moderate & Low & Low & Low & Low \\
\hline
\end{tabular}

only indicated to a relatively large orifice of EAF with mucosal protrusion. Moreover, the complicated manufacturing process limited the promotion of this technology to other medical centers so that the current clinical evidence is low.

As an alternative, injection molding stent was invented and was easily promoted because the molds can be prepared in advance based on different anatomic parameters of EAF with the $\beta$ ranging from $70^{\circ}$ to $180^{\circ}$ and the parameters ranging from $1 \mathrm{~cm}$ to $3 \mathrm{~cm}$. The extreme case still requires a $3 \mathrm{D}$ printing stent or to customize a mold. As shown in Figure 6A, the mold consists of two shells and one core. The shell is tailored with the holes at the edge for fixation and the hole in the middle for injection of silica gel, which fills up the space between the shell and core and then is solidified at $100^{\circ} \mathrm{C}$ for $30 \mathrm{~min}$. The mold is fabricated using a 3D printer in FDM and made of the polylactic acid (PLA) (Figure 6B). Figure 6C demonstrates the manufacturing process of a stent casted by a mold from the mold installation, silica gel injection, to the mold removal. The silica gel product is featured on its elasticity so that the stent is easily implanted into EAF (Figure 6D). This technique consumes less time (merely $1 \mathrm{~h}$ ) to access a personalized stent compared with the $3 \mathrm{D}$ printing stent. Because of a similar size to the $3 \mathrm{D}$ printing stent, this injection molding stent is also only indicated to a relatively large orifice of EAF with mucosal protrusion. Table 1 lists the comparisons among all mentioned approaches from technical and clinical perspectives, and the choice is based on the individual conditions of patients.

\section{OUTLOOK FOR EAF MANAGEMENT}

Although the progress has been achieved on EAF isolation, the technique still needs to be further optimized. First, due to the limited contrast between intestinal tissues and the surrounding soft tissues, current imaging methods cannot extract the intestinal photos directly so that we have to design the STL file separately using the Solidwork software, which is time-consuming. Magnetic resonance imaging (MRI) technology has shown higher sensitivity in distinguishing GI fistula from soft tissues $(40,41)$, and is promising to provide a more precise tool for the measurement of EAF anatomy. When combined with artificial intelligence, the ultimate goal is to achieve the STL file of fistula stents directly from the fistula images in a quick and convenient manner (4245). Moreover, the small size of EAF's orifice hinders the implantation of the fistula stent. To address this issue, elastic and shape-memory biomaterials should be tested for production of the stent (46-48). In addition, the clinical trials based on these techniques are urgently needed for providing more evidence.

\section{CONCLUSION}

In this review, we introduced several isolation approaches for the management of EAF after open abdomen including NPWT, fistuloclysis, fistula patch, surgical covered stent, 3D printing stent, and injection molding stent. The choice of these approaches should consider the condition of EAF, general body habitus, and the treatment purpose. The fistula stent is a new solution with promising functions in the maintenance of the GI tract physical integrity. The cooperation between surgeons and engineers is advocated to promote the improvement and application of these techniques.

\section{AUTHOR CONTRIBUTIONS}

$\mathrm{JR}$ and XW conceived this review. JH organized literatures and wrote this review. HR organized the photographs and the table. YJ participated in the discussion. All authors contributed to the article and approved the submitted version.

\section{ACKNOWLEDGMENTS}

We thank to Yanhan Ren in Rosalind Franklin University of Medicine and Science, USA for his help in language editing. We also appreciate the financial supports from the National Major Scientific and Technological Special Project for Significant 
New Drugs Development (2018ZX09J18111-04), General Project of Military Logistics Research (CLB19J025), Innovation Project of Military Medicine (16CXZ007), Distinguished

\section{REFERENCES}

1. Coccolini F, Montori G, Ceresoli M, Catena F, Moore EE, Ivatury R, et al. The role of open abdomen in non-trauma patient: WSES consensus paper. World J Emerg Surg. (2017) 12:39. doi: 10.1186/s13017-017-0146-1

2. Mathes SJ, Steinwald PM, Foster RD, Hoffman WY, Anthony JP. Complex abdominal wall reconstruction: a comparison of flap and mesh closure. Ann Surg. (2000) 232:586-96. doi: 10.1097/00000658-200010000-00014

3. Choi JJ, Palaniappa NC, Dallas KB, Rudich TB, Colon MJ, Divino CM. Use of mesh during ventral hernia repair in clean-contaminated and contaminated cases: outcomes of 33,832 cases. Ann Surg. (2012) 255:176-80. doi: 10.1097/SLA0b013e31822518e6

4. Huang J, Li Z, Hu Q, Chen G, Ren Y, Wu X, et al. Bioinspired antidigestive hydrogels selected by a simulated gut microfluidic chip for closing gastrointestinal fistula. iScience. (2018) 8:40-8. doi: 10.1016/j.isci.2018.09011

5. Petersson P, Petersson U. Dynamic fascial closure with vacuum-assisted wound closure and mesh-mediated fascial traction (VAWCM) treatment of the open abdomen-an updated systematic review. Front Surg. (2020) 7:577104. doi: 10.3389/fsurg.2020577104

6. Coccolini F, Ceresoli M, Kluger Y, Kirkpatrick A, Montori G, Salvetti F, et al. Open abdomen and entero-atmospheric fistulae: an interim analysis from the International Register of Open Abdomen (IROA). Injury. (2019) 50:160-6. doi: 10.1016/j.injury.2018.09.040

7. Li Z, Wu C, Liu Z, Li Z, Peng X, Huang J, et al. A polypropylene mesh coated with interpenetrating double network hydrogel for local drug delivery in temporary closure of open abdomen. RSC Adv. (2020) 10:1331-40. doi: 10.1039/C9RA10455K

8. Montori G, Allievi N, Coccolini F, Solaini L, Campanati L, Ceresoli $\mathrm{M}$, et al. Negative pressure wound therapy versus modified barker vacuum pack as temporary abdominal closure technique for open abdomen management: a four-year experience. BMC Surg. (2017) 17:86. doi: 10.1186/s12893-017-0281-3

9. Rather HA, Thakore R, Singh R, Jhala D, Singh S, Vasita R. Antioxidative study of Cerium Oxide nanoparticle functionalised PCL-Gelatin electrospun fibers for wound healing application. Bioact Mater. (2018) 3:201-11. doi: 10.1016/j.bioactmat.2017.09006

10. Guo K, Gong W, Zheng T, Hong Z, Wu X, Ren H, et al. Clinical parameters and outcomes of necrotizing soft tissue infections secondary to gastrointestinal fistulas. BMC Infect Dis. (2019) 19:597. doi: 10.1186/s12879-019-4248-0

11. Hodgkinson JD, Oke SM, Warusavitarne J, Hanna GB, Gabe SM, Vaizey CJ. Incisional hernia and enterocutaneous fistula in patients with chronic intestinal failure: prevalence and risk factors in a cohort of patients referred to a tertiary centre. Colorectal Dis. (2019) 21:1288-95. doi: 10.1111/codi14735

12. Coccolini F, Roberts D, Ansaloni L, Ivatury R, Gamberini E, Kluger Y, et al. The open abdomen in trauma and non-trauma patients: WSES guidelines. World J Emerg Surg. (2018) 13:7. doi: 10.1186/s13017-018-0167-4

13. Gomes-Porras M, Cardenas-Salas J, Alvarez-Escola C. Somatostatin analogs in clinical practice: a review. Int J Mol Sci. (2020) 21:1682. doi: $10.3390 /$ ijms 21051682

14. Gribovskaja-Rupp I, Melton GB. Enterocutaneous Fistula: proven Strategies and Updates. Clin Colon Rectal Surg. (2016) 29:130-7. doi: 10.1055/s-0036-1580732

15. Dellinger RP, Schorr CA, Levy MM. A users' guide to the 2016 Surviving Sepsis Guidelines. Intensive Care Med. (2017) 43:299-303. doi: 10.1007/s00134-017-4681-8

16. Vassalos A, Rooney K. Surviving sepsis guidelines 2012. Crit Care Med. (2013) 41:e485-6. doi: 10.1097/CCM0b013e31829644e8

17. Wu X, Ren J, Gu G, Wang G, Han G, Zhou B, et al. Autologous platelet rich fibrin glue for sealing of low-output enterocutaneous fistulas: an observational cohort study. Surgery. (2014) 155:434-41. doi: 10.1016/j.surg.2013.09001
Scholars Foundation of Jiangsu Province (JCRCB2016006), and Postgraduate Research \& Practice Innovation Program of Jiangsu Province (KYCX20_0150).
18. Wu X, Ren J, Yao G, Zhou B, Wang G, Gu G, et al. Biocompatibility, biodegradation, and neovascularization of human single-unit plateletrich fibrin glue: an in vivo analysis. Chin Med J. (2014) 127:408-11. doi: 10.3760/cma.j.issn.0366-6999.20130412

19. Ren J, Wu X, Wang G, Chen J, Gu G, Li J. Fistula fiberscopeassisted percutaneous glue sealing for enterocutaneous fistulas: a case report. Surg Laparosc Endosc Percutan Tech. (2013) 23:e235-6. doi: 10.1097/SLE0b013e31828f6efa

20. Huang J, Jiang Y, Liu Y, Ren Y, Xu Z, Li Z, et al. Marine-inspired molecular mimicry generates a drug-free, but immunogenic hydrogel adhesive protecting surgical anastomosis. Bioact Mater. (2021) 6:770-82. doi: 10.1016/j.bioactmat.2020.09010

21. Bobkiewicz A, Walczak D, Smolinski S, Kasprzyk T, Studniarek A, BorejszaWysocki M, et al. Management of enteroatmospheric fistula with negative pressure wound therapy in open abdomen treatment: a multicentre observational study. Int Wound J. (2017) 14:255-64. doi: 10.1111/iwj 12597

22. Leang YJ, Bell SW, Carne P, Chin M, Farmer C, Skinner S, et al. Enterocutaneous fistula: analysis of clinical outcomes from a single Victorian tertiary referral centre. Anz J Surg. (2018) 88:E30-3. doi: 10.1111/ans13686

23. Visschers RG, Olde DS, Winkens B, Soeters PB, van Gemert WG. Treatment strategies in 135 consecutive patients with enterocutaneous fistulas. World $J$ Surg. (2008) 32:445-53. doi: 10.1007/s00268-007-9371-1

24. Wirth U, Renz BW, Andrade D, Schiergens TS, Arbogast H, Andrassy J, et al. Successful treatment of enteroatmospheric fistulas in combination with negative pressure wound therapy: experience on 3 cases and literature review. Int Wound J. (2018) 15:722-30. doi: 10.1111/iwj12916

25. Cresci GA, Martindale RG. Metabolic and nutritional management of a patient with multiple enterocutaneous fistulas. Nutrition. (1997) 13:446-8, 448-9. doi: 10.1016/S0899-9007(97)00094-4

26. Sharma P, Davidson R, Davidson J, Keane C, Liu C, Ritchie SR, et al. Novel chyme reinfusion device for gastrointestinal fistulas and stomas: feasibility study. Br J Surg. (2020) 107:1199-210. doi: 10.1002/bjs11516

27. Mettu SR. Fistuloclysis can successfully replace parenteral feeding in the nutritional support of patients with enterocutaneous fistula. Br J Surg. (2004) 91:625-31. doi: 10.1002/bjs.4520

28. Bhat S, Sharma P, Cameron NR, Bissett IP, O'Grady G. Chyme Reinfusion for Small Bowel Double Enterostomies and Enteroatmospheric Fistulas in Adult Patients: a systematic review. Nutr Clin Pract. (2020) 35:254-64. doi: $10.1002 / \mathrm{ncp} 10417$

29. Ortiz LA, Zhang B, McCarthy MW, Kaafarani H, Fagenholz P, King DR, et al. Treatment of enterocutaneous fistulas, then and now. Nutr Clin Pract. (2017) 32:508-15. doi: $10.1177 / 0884533617701402$

30. Polk TM, Schwab CW. Metabolic and nutritional support of the enterocutaneous fistula patient: a three-phase approach. World J Surg. (2012) 36:524-33. doi: 10.1007/s00268-011-1315-0

31. Subramaniam MH, Liscum KR, Hirshberg A. The floating stoma: a new technique for controlling exposed fistulae in abdominal trauma. J Trauma. (2002) 53:386-8. doi: 10.1097/00005373-200208000-00037

32. Wang G, Ren J, Liu S, Wu X, Gu G, Li J. "Fistula patch". J Trauma Acute Care. (2013) 74:1175-7. doi: 10.1097/TA0b013e318282705e

33. Rebibo L, Wacrenier A, Thiebault H, Delcenserie R, Regimbeau JM. Combined endoscopic and surgical covered stent placement: a new tailored treatment for enteroatmospheric fistula in patients with terminal ileostomy. Endoscopy. (2017) 49:E35-6. doi: 10.1055/s-0042-121489

34. Huang JJ, Ren JA, Wang GF, ZA Li, Wu XW, Ren HJ, et al. 3Dprinted "fistula stent" designed for management of enterocutaneous fistula: an advanced strategy. World J Gastroenterol. (2017) 23:7489-94. doi: $10.3748 /$ wjg.v23.i417489

35. Xu ZY, Ren HJ, Huang JJ, ZA Li, Ren JA. Application of a 3Dprinted "fistula stent" in plugging enteroatmospheric fistula with open 
abdomen: a case report. World J Gastroenterol. (2019) 25:1775-82. doi: 10.3748/wjg.v25.i141775

36. Derakhshanfar S, Mbeleck R, Xu K, Zhang X, Zhong W, Xing M. $3 \mathrm{D}$ bioprinting for biomedical devices and tissue engineering: a review of recent trends and advances. Bioact Mater. (2018) 3:144-56. doi: 10.1016/j.bioactmat.2017.11008

37. Wei $\mathrm{L}$, Wu S, Kuss $\mathrm{M}$, Jiang $\mathrm{X}$, Sun $\mathrm{R}$, Reid $\mathrm{P}$, et al. 3D printing of silk fibroin-based hybrid scaffold treated with platelet rich plasma for bone tissue engineering. Bioact Mater. (2019) 4:256-60. doi: 10.1016/j.bioactmat.2019.09001

38. Oksuzoglu G, Arat A, Iret D, Sivri B. Fistulography in a difficult case: using a new, practical, and inexpensive device. AJR Am J Roentgenol. (1996) 167:281. doi: 10.2214/ajr.167.18659406

39. Liang C, Lu Y, Zhao B, Du Y, Wang C, Jiang W. Imaging of anal fistulas: comparison of computed tomographic fistulography and magnetic resonance imaging. Korean J Radiol. (2014) 15:712-23. doi: 10.3348/kjr.2014. 15.6712

40. Gatti M, Allois L, Carisio A, Dianzani C, Garcia MM, Ruggirello I, et al. Magnetic resonance enterography. Minerva Gastroenterol Dietol. (2019) 65:319-34. doi: 10.23736/S1121-421X.1902639-4

41. Konan A, Onur MR, Ozmen MN. The contribution of preoperative MRI to the surgical management of anal fistulas. Diagn Interv Radiol. (2018) 24:321-7. doi: 10.5152/dir.201818340

42. Wang L, Yang S, Yang S, Zhao C, Tian G, Gao Y, et al. Automatic thyroid nodule recognition and diagnosis in ultrasound imaging with the YOLOv2 neural network. World J Surg Oncol. (2019) 17:12. doi: 10.1186/s12957-019-1558-z

43. Su L, Dong Q, Zhang H, Zhou X, Chen Y, Hao X, et al. Clinical application of a three-dimensional imaging technique in infants and young children with complex liver tumors. Pediatr Surg Int. (2016) 32:387-95. doi: 10.1007/s00383-016-3864-7

44. Neftci EO. Data and power efficient intelligence with neuromorphic learning machines. iScience. (2018) 5:52-68. doi: 10.1016/j.isci.2018.06010

45. Goodhill GJ. Theoretical models of neural development. iScience. (2018) 8:183-99. doi: 10.1016/j.isci.2018.09017

46. Wu Y, Wang L, Zhao X, Hou S, Guo B, Ma PX. Self-healing supramolecular bioelastomers with shape memory property as a multifunctional platform for biomedical applications via modular assembly. Biomaterials. (2016) 104:1831. doi: 10.1016/j.biomaterials.2016.07011

47. Lendlein A, Behl M, Hiebl B, Wischke C. Shape-memory polymers as a technology platform for biomedical applications. Expert Rev Med Devices. (2010) 7:357-79. doi: 10.1586/erd.108

48. Zhao YQ, Yang JH, Ding $\mathrm{X}$, Ding $\mathrm{X}$, Duan $\mathrm{S}$, Xu FJ. Polycaprolactone/polysaccharide functional composites for lowtemperature fused deposition modelling. Bioact Mater. (2020) 5:185-91. doi: 10.1016/j.bioactmat.2020.02006

Conflict of Interest: The authors declare that the research was conducted in the absence of any commercial or financial relationships that could be construed as a potential conflict of interest.

Copyright $\odot 2021$ Huang, Ren, Jiang, Wu and Ren. This is an open-access article distributed under the terms of the Creative Commons Attribution License (CC BY). The use, distribution or reproduction in other forums is permitted, provided the original author(s) and the copyright owner(s) are credited and that the original publication in this journal is cited, in accordance with accepted academic practice. No use, distribution or reproduction is permitted which does not comply with these terms. 